MR. DREW PORTMAN (Orcid ID : 0000-0001-7373-0424)

Article type : Research

6

Nutritional and functional properties of cookies made using down-graded

9 lentil - A candidate for novel food production and crop utilisation

D. Portman 1, 2*, P. Maharjan², L. McDonald², S. Laskovska ${ }^{2}$, C. Walker ${ }^{2}$, H. Irvin², C.

Blanchard $^{1}$, M. Naiker ${ }^{3}$, J.F. Panozzo ${ }^{2}$

${ }^{1}$ School of Biomedical Science, Charles Sturt University, Wagga Wagga, NSW 2650, Australia.

${ }^{2}$ Agriculture Victoria Research, Grain Innovation Park, Horsham, VIC, Australia.

${ }^{3}$ School of Health, Medical and Applied Science, Central Queensland University, Rockhampton, QLD 4702, Australia.

*Corresponding author: E-mail: aportman@csu.edu.au

ABSTRACT

Background and objectives: Lentil (Lens culinaris M.) are a high-value grain used traditionally as a minimally processed product. Lentil crops are well-suited to Mediterraneantype climates with mild winters and hot dry summers which results in the production of highvalue grain. However, extreme weather conditions, such as frost, can impact on the lentil seed e.g. a darkened seed colour and distorted seed shape resulting in a downgrade of its market value. The quality parameters of lentil when milled as wholemeal flour is not reliant on visual or physical seed traits such as seed size and color which impact on the market value in traditional market specifications. Instead, quality parameters such as those applied in the assessment of wheat, these include flour yield and colour would be appropriate parameters to determine the value of lentil flour. It is proposed that flour, even from down-graded lentil could be supplemented with wheat flour and used to enhance the quality profile of baked products including breads, pastas and cookies.

This is the author manuscript accepted for publication and has undergone full peer review but has not been through the copyediting, typesetting, pagination and proofreading process, which may lead to differences between this version and the Version of Record. Please cite this article as doi: 10.1002/CCHE.10232

This article is protected by copyright. All rights reserved 
32 Findings: This study investigated the use of premium and frost damaged lentil flour in cookie making. Overall cookies made from wheat-lentil composite blends resulted in flatter and wider cookies that were darker than the cookies made from $100 \%$ wheat flour. Cookies made by incorporating lentil and wheat flour resulted in a significant increase in total protein, insoluble fiber and oligosaccharides $(p<0.05)$. In addition, the phenolic acids kaempferol and procyanidin were detected in cookies made using wheat-lentil contributing to an increase in antioxidant activity $(p<0.05)$. These phenolic acids were not detected in cookies made from $100 \%$ wheat flour. Our results show that using concentrations of up to $25 \%$ lentil flour resulted in cookies that had expectable hardness and colour characteristics in comparison with a $100 \%$ wheat biscuit.

42 Conclusion: This research showed that the nutritional value and functional properties of cookies can be significantly enhanced by using either premium or down-graded lentil and the quality of the cookies was not impacted by the market-grade of the raw material.

\section{Significance and novelty}

Investigations into the use of pulse flours such as lentil in novel food products including pasta and snack foods is gaining popularity particularly by the health-conscious consumer. The visual appearance of lentil is not critical when utilised in such products. Lentil that have been visually or physically affected by adverse weather conditions, but its nutritional and functional value has not been compromised may prove a viable inclusion in the creation of highly nutritious food alternatives. The use of down-graded lentil as flour in novel food production could ultimately add value to pulse grain affected by adverse environmental conditions.

KEY WORDS

Lentil, Frost, Protein, Fiber, Oligosaccharides, Kaempferol, Procyanidin

\section{INTRODUCTION}

Premium quality lentil seeds (Figure 1A) are classified based on physical seed quality traits relating to size, shape, colour and absence of defective seeds (McDonald, Panozzo, Salisbury, \& Ford, 2016). Seed characteristics and grain yield are genetically determined but strongly influenced by environmental conditions. Adverse conditions such as frost, impact on the appearance of the harvested seed can create a market challenge for growers (Nuttall et al., 
2018). Frost events are a particular concern for lentil growers, as the economic loss to growers through frost-affected lentil crops in Australia is estimated to be US \$250 million per annum (Delahunty, Perry, Wallace, Brand, \& Nuttall, 2019).

\section{(Insert FIGURE 1)}

The investigation into the alternate use of pulse flour such as wheat-based products including pasta, breakfast cereals and snack foods is gaining popularity in western countries (Dziki, Różyło, Gawlik-Dziki, \& Świeca, 2014; Sparvoli et al., 2016; Tosh \& Yada, 2010). Research has shown that pulses including lentil are highly nutritious and have functional properties that may play a protective role in human health (Rochfort \& Panozzo, 2007; Takruri \& Issa, 2013). An opportunity exists to exploit the compositional components of down-graded pulses such as frost-damaged lentil seeds to produce wheat-based food products. Classifying damaged seed based on its proximal composition for use as a flour additive could provide a substantial nutritional and dietary supplement whilst concurrently improving returns for growers and lowering the cost of production.

\section{MATERIALS AND METHODS}

Two grades of commercially available red lentil (Lens culinaris M.) were used in this study. The samples consisted of premium-grade lentil with a Grade 1 classification and downgraded frost-affected lentils classified as rejects and destined for stock feed. Lentil seeds were cleaned using a vacuum separator (KimSeed, WA, Australia) to remove any field debris. Lentil seeds were milled to flour using a cyclone mill fitted with a $0.5 \mathrm{~mm}$ screen (Laboratory Mill 120; Perten Instruments, Huddinge, Sweden). The cotyledon was not separated from the seed coat and seeds were milled whole. Composite wheat-lentil flours were prepared by blending high-grade soft baking flour (II Molino Chiavazza, Casalgrasso, Italy) with either premium-grade or frost affected lentil flour (Table 1).

\section{(Insert Table 1)}

\section{Preparation of Cookies}

Cookies were made from doughs prepared with wheat flour supplemented with either premium or frost affected lentil-f(dnsent dT only wheat flour as a control. The cookies were baked according to International Method No. 10-50.05 AACC (AACC, 2000). Cookie flours along with additional ingredients (Table 2) were mixed using a Dough-LAB 3100 mixer (Perten Instruments, Huddinge, Sweden). The dough was manually sheeted to $1 \mathrm{~mm}$ thickness and cookies were cut using a round cutter 
with an internal diameter of $49 \mathrm{~mm}$. Cookies were baked for 10 minutes in a pilot scale electric baking oven (Rotel, APV Inc., QLD, Australia) at $210^{\circ} \mathrm{C}$.

\section{Physical Analysis}

The physical characteristics were determined 24 hours after baking. The thickness of individual cookies was measured using a digital height gauge and their weights recorded. Cookie hardness was measured using a TA-XT2 Texture Analyzer (Stable Micro Systems, Surrey, UK) in accordance with the American Institute of Baking (AIB) standard procedure for hardness of cookies (AIB, 2012). The average force required to snap each cookie was expressed as a measure of firmness $(\mathrm{N})$. Images of each cookie were taken using a digital camera and analysed with MATLAB R2016b software (MathWorks, MA, USA) for diameter and area. The lightness of each cookie was measured using the Commission International del'eclairage tristimulus color parameters (CIE) L* with a Chroma Meter CR-410 colorimeter (Minolta Co., Osaka, Japan).

\section{Total Protein Analysis}

Total protein content of cookies was measured using the Dumas combustion method AACC 46-30.01 (AACC International, 2002) and was performed using a Leco TruMac analyzer (Leco Corp, St Joseph, MI, USA). Moisture content was determined using a thermogravimetric analyser (TGA) (Leco Corp, St Joseph, MI, USA). Total protein was reported on a \% dry basis and all sample evaluations were completed in triplicate.

\section{Neutral Detergent Fiber Analysis (NDF)}

Insoluble fiber (lignin, hemicellulose and cellulose) contained in cookies was measured using the ANKOM Neutral Detergent Fiber (NDF) assay as described by (Van Soest \& Robertson, 1981).

\section{Analysis of Raffinose Family Oligosaccharides (RFOs)}

The raffinose family oligosaccharides (RFOs) was measured by Ultra Performance Liquid Chromatography/Evaporative Light Scattering Detection (UPLC/ELSD) using the method as described in Portman et al., (2019).

\section{Phenolic Acid Extraction}

Ground cookies $(0.25 \mathrm{~g})$ was weighed into $15 \mathrm{~mL}$ polyethylene tubes. One $\mathrm{mL}$ of $70 \%$ acetone was added and the sample was vortexed and placed on a thermo shaker (Thermo Scientific, Australia) set at $5000 \mathrm{rpm}$ at room temperature for 1 hour. Samples were then centrifuged at $4000 \mathrm{rcf}$ (Eppendorf Centrifuge 5810, Hamburg, Germany) for 5 minutes and the supernatant transferred to $15 \mathrm{~mL}$ tubes. This extraction step was repeated, and the 
132 supernatant collected. An aliquot $(1 \mathrm{~mL})$ of pooled supernatant was dried at $60^{\circ} \mathrm{C}$ under a nitrogen gas stream in a heated block (Ratek Instruments, Victoria, Australia). After drying, samples were resuspended in $1 \mathrm{~mL} \mathrm{10 \%} \mathrm{methanol} \mathrm{and} \mathrm{filtered} \mathrm{through} 0.22 \mu \mathrm{m}$ PTF syringe filter (FILTER-BIOß) into UPLC vials for analysis.

137 Identification of phenolic acids in cookies was undertaken as described by (Maharjan, Penny, 138 Partington, \& Panozzo, 2019). All analyses were performed on a Waters UPLC ACQUITY 139 system (Waters Corporation, Milford, MA, USA) with Photodiode array detector (PDA) and 140 ACQUITY QDa mass detector. Separation was achieved using a UPLC-BEH C18 column

141 (2.1 X 50mm, $1.8 \mu \mathrm{m})$. The mobile phase consisted of (solvent A) acetonitrile with $0.1 \%$ 142 acetic acid and (solvent B) MilliQ water with $0.1 \%$ acetic acid. Peaks were identified based 143 on their molecular weight and UV profiles. All data was processed using Empower 3 144 software.

\section{Ferric Reducing Antioxidant Power Assay (FRAP)}

146 The antioxidant activity of wheat-lentil cookies was determined using the FRAP method described by Benzie and Strain (1996) with some modifications. The FRAP reagent was 148 prepared by mixing 300mM acetate buffer at $\mathrm{pH} 3.65,20 \mathrm{mM}$ ferric chloride and $10 \mathrm{mM}$ of 149 2,4,6-Tris(2-pyridyl)-s-triazine (TPTZ) (Sigma-Aldrich, Sydney, Australia) in the ratio of 10:

$1501 ; 1$. Ferrous sulphate solution was used as a standard at concentrations of $(0.1,0.2,0.4,0.6$, 1510.8 , and $1 \mathrm{mM}$ ). A $0.1 \mathrm{~mL}$ aliquot of sample and $3 \mathrm{~mL}$ of FRAP reagent were combined in a 152 test tube and incubated at $37{ }^{\circ} \mathrm{C}$ for 4 minutes. One $\mathrm{mL}$ aliquot of each sample was transferred to a 96-well microplate and the absorbance was measured at $593 \mathrm{~nm}$ using a micro-plate reader (Multiscan GO, Thermo Scientific, USA). The antioxidant power of samples was calculated using ferrous sulphate standard calibration curves and expressed as

$156 \mathrm{Fe}^{+}$equivalent $\mu \mathrm{mol} / 100 \mathrm{~g}$.

\section{Statistics}

158 All data was analysed by analysis of variance (ANOVA) with GenStat statistical software $15917^{\text {th }}$ edition (VSN International, Hempstead, UK). Means were analyzed for the least 160 significant difference at a probability level of $p<0.05$. Results are expressed as mean values $161 \pm S D$. All analyses were completed in triplicate unless otherwise stated.

\section{RESULTS AND DISCUSSION}

\section{Cookie Quality}


164 For all cookie traits, the addition of lentil flour resulted in a significant reduction in cookie height $(p<0.05)$, and a significant reduction in cookie weight $(p<0.05)$ compared to the cookies baked with $100 \%$ wheat flour. The addition of lentil also caused a significant increase in hardness $(p<0.05)$, and a significant increase in cookie diameter and surface area $(p<0.05)$ (Table 3). Cookies containing lentil flour became significantly darker as the proportion of lentil flour increased $(p<0.05)$. Overall this study showed that the addition of lentil flour resulted in cookies that were harder, thinner, and darker than a cookie made from $100 \%$ wheat flour (Figure 2).

The main aim of the study was to show the potential applications for both premium and down-graded lentil flour in producing cookies. This study was a proof of concept and sensory evaluation was not performed. Although wheat-lentil composite cookies are in commercial production, further work using sensory evaluation would be necessary to assess the palatability of cookies using a wheat flour composite made with down-graded lentils. The observed changes in the physical attributes of cookies made using lentil flour is likely due to a combination of interactive factors. Competition for water-binding between lentil and wheat proteins (Portman et al., 2018; Turfani, Narducci, Durazzo, Galli, \& Carcea, 2017), the dilution of gluten reduced the hydrophilic regions available for water binding (Portman et al.; Tuhumury, 2014) and an increase in Maillard reaction due to an increase in protein and carbohydrate content (Martins, Jongen, \& Van Boekel, 2000; Portman et al., 2018) all contribute to these changes.

Protein and Fiber Content of

Cookies

The proximal analyses of protein and neutral detergent fibre (NDF) of cookies are presented in (Figure 3). As expected, the addition of lentil flour regardless of lentil-grade resulted in an increase in both total protein and NDF of cookies compared to a $100 \%$ wheat cookie $(p<$ 0.05). However, no significant difference in the concentration of protein or NDF fiber was observed when comparing cookies made from flour of either premium or frost damaged lentil.

3

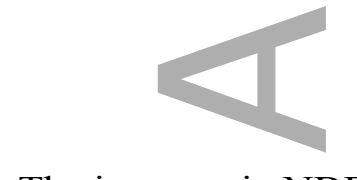

\section{(Insert FIGURE 3)}

The increase in NDF content caused by the addition of lentil flour is predominantly due to the inclusion of the seed coat material from lentil, which contains cellulose, hemicellulose and lignin fibers (Dalgetty \& Baik, 2003). The total dietary fibre (TDF) found in lentils is reported to be around 15\% (Williams, Mikkelsen, Flanagan, \& Gidley, 2019). In humans, it is 
commonly stated that the majority of insoluble dietary fiber (IDF) undergoes microbial fermentation in the large intestine (Tosh \& Yada, 2010), which is largely due to the number of microbes and their activity. However, Matthews, Howarth, and Butler (2012) describe a multiple pathway of IDF along with other dietary macronutrients with fermentation occurring at a lower rate in the stomach and small intestine. The ability to ferment IDF is not only based on solubility but its structure, not all forms of IDF are fermented in the human digestive system (Matthews et al., 2012). Microbial fermentation of IDF can provide many health benefits (Rochfort, Ezernieks, Neumann, \& Panozzo, 2011). Such benefits may be found in the production of short-chain fatty acids (SCFAs), which acts as an antiinflammatory ( $\mathrm{Li}$ et al., 2018), suppresses blood cholesterol absorption (Hara, Haga, Aoyama, \& Kiriyama, 1999) and may reduce tumour growth (Matthews et al., 2012). In this study Insoluble fibre in wheat-lentil composite cookies was measured by the Neutral Detergent Fibre method (NDF). This method of fibre analysis measures most structural components found in plant cell walls, predominantly lignin, hemicellulose and cellulose. Thus, NDF was used as a rapid screen closely related to dietary fibre but does not measure the content of other constituents such as pectin (Van Soest \& Robertson, 1981). Therefore, product development arising from this research would require a more mainstream analyses to measure total dietary fibre, such as the AACC total dietary fibre (TDF) method, 32-05.01 (McCleary, 2010; Menkovska et al., 2017) or with the Megazyme K-TDFR total dietary fibre assay (Hollmann, Themeier, Neese, \& Lindhauer, 2013).

\section{Raffinose Family Oligosaccharides (RFOs)}

The addition of lentil flour introduced the Raffinose Family Oligosaccharides ( RFO $\left._{S}\right)$ to the wheat-lentil composite flour. Wheat predominantly contains the reducing sugars fructose, glucose, sucrose and maltose but no RFOs. The $\alpha$-galacto-oligosaccharides from lentil detected include raffinose, stachyose verbascose, and the pinitol digalactoside ciceritol (Figure 4).

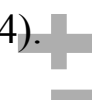

\section{(Insert FIGURE 4)}

Increasing the concentration of lentil flour significantly increased RFO concentration $(p<$ 0.05). However, no significant difference in RFO concentration was observed at any concentration level between cookies made from either premium or frost damaged lentil flour (Table 4).

(Insert TABLE 4) 
232 A previous bread study using wheat-lentil composite flours demonstrated that RFOs with the 233 exception of ciceritol, were significantly reduced through the fermentation process (Portman, 234 Blanchard, Maharjan, Naiker, \& Panozzo, 2019). However, cookies prepared according to 235 AACC method 10-50.05 (AACC, 2000) do not undergo fermentation and therefore the 236 concentration of RFOs was not significantly reduced in wheat-lentil cookies.

237 The presence of RFOs in flour and baked products can be both problematic and beneficial. A 238 high concentration of RFOs can contribute to Irritable Bowel Syndrome (IBS). Symptoms 239 include abdominal bloating and diarrhea (Fleming, 1981; Gilani, Xiao, \& Cockell, 2012). IBS

240 is caused by the production of hydrogen, carbon dioxide and methane gasses when RFOs are 241 fermented in the colon (Gilani et al., 2012). Conversely, fermentation of RFOs in the colon 242 have been associated with several health benefits in humans when fermented in the large 243 intestine (Siva et al., 2018; Siva \& Thavarajah, 2018). These include improving gut health by 244 increasing levels of lactobacilli and fidobacteria (Berrios, Morales, Cámara, \& Sánchez-Mata, 245 2010), a reduction of opportunistic pathogens including enterobacteria (Berrios et al., 2010), protection against reactive oxygen spices (ROS) through the reduction of $\mathrm{N}$ - nitroso (NOC) compounds formed in the gut (Van Loo et al., 1999), and aiding in stool softening (Berrios et al., 2010). Additionally there is evidence that RFO can stimulate the innate immune system by their interactions with Tol-like receptors (TLRs) (Rochfort \& Panozzo, 2007). The addition of fermentable carbohydrates such as RFOS may also block the fermentation of protein which can lead to the generation of cancer-promoting metabolites (Matthews et al., 2012).

\section{Phenolic Compounds}

254 Three prominent phenolic compounds were detected in cookies made from either premium of frost damaged lentil that were not detected in a $100 \%$ wheat cookie (Figure 5). The three compounds were tentatively identified as the dietary flavanols kaempferol trihexose and kaempferol glycoside as well as the flavonoid procyanidin. These compounds have previously been reported in lentils (Duenas, Hernandez, \& Estrella, 2006; Mirali, Ambrose,

259 Wood, Vandenberg, \& Purves, 2014; Żuchowski, Pecio, Reszczyńska, \& Stochmal, 2016), and are summarised below (Table 5). Epidemiological studies have shown a high association between the consumption of fruits and pulses that contain kaempferol derivatives and reduce risk of disease including lung, gastric, ovarian

(Insert TABLE 5) 
cancer and cardiovascular disease (Calderon-Montano, Burgos-Morón, Pérez-Guerrero, \& López-Lázaro, 2011). For example, a case study of 558 lung cancer sufferers, found that dietary intake of approximately $2 \mathrm{mg}$ of kaempferol daily was inversely associated with lung cancer risk (Cui et al., 2008). Kaempferol and procyanidin derivatives have also been identified as potent superoxide scavengers in low concentration (Calderon-Montano et al., 2011; Rao, Santhakumar, Chinkwo, \& Blanchard, 2018). Superoxides are highly reactive and can damage DNA, protein and lipids (Aniya et al., 2005). Research has also identified the potential protective mechanisms of procyanidin to include anti-diabetic, anti-platelet, anticholesterol, anti-microbial, and anti-aging properties (Ma \& Zhang, 2017).

\section{Ferric Reducing Antioxidant Power (FRAP)}

The antioxidant activity of wheat-lentil cookies was measured by their ability to reduce Iron 3 oxide (Fe III) to Iron 2 oxide (Fe II) forming a ferrous- tripyridyltriazine complex (FeII TPTZ). The results (Figure 6) demonstrated a significant increase in antioxidant activity with increased proportions of lentil flour $(P<0.05)$. Importantly, no significant difference in antioxidant activity was observed between cookies made from either premium or frost damaged lentil.

\section{(Insert FIGURE 6)}

\section{Conclusion}

Cookies made using either premium and frost damaged lentil had higher concentrations of protein and fiber compared to cookies made from $100 \%$ wheat. No significant difference was observed in in percent protein or total fiber when comparing cookies made from either premium or frost damaged lentil flour. Furthermore, combining wheat and lentil flour in cookie making resulted in the addition of RFOs, which are considered soluble dietary fiber and help promote regulatory function in humans. Wheat-lentil composite cookies introduced the phenolic compounds kaempferol trihexose, kaempferol glycoside and procyanidin which were not detected in cookies made from $100 \%$ wheat. The potential beneficial roles of these phenolic compounds in human health has been widely published. Down-graded pulses such as frost-damaged lentil can be milled to high-grade flour comparable to using premium grade lentil. Thereby enhancing the nutritional and functional value of wheat-based products while increasing the potential value of damaged pulse crops.

\section{Acknowledgments}

The authors would like to acknowledge Mr Mick Finnigan from AGT Foods Australia for providing the lentil samples. The authors would also like to acknowledge the technical staff 
300 from the Seed Phenomics and Quality Traits laboratory Agriculture Victoria for their

301 invaluable assistance.

302 Funding. This research was funded by the Australian Research Council Industry 303 Transformation Centre for Functional Grains [Identifier Number: IGI40100027] and the

304 Victorian Government Department of Jobs, Precincts and Regions, Agriculture Victoria

305 Research. Drew Portman is a recipient of the Australian Research Council scholarship 306 through Charles Sturt University. The authors declare no conflict of interest.

\section{REFERENCES}

308 AACC, I. (2000). Approved Methods of the AACC. Association of Cereal Chemists, St. Paul.

Aniya, Y., Koyama, T., Miyagi, C., Miyahira, M., Inomata, C., Kinoshita, S., \& Ichiba, T. (2005). Free radical scavenging and hepatoprotective actions of the medicinal herb, Crassocephalum crepidioides from the Okinawa Islands. Biological and Pharmaceutical Bulletin, 28(1), 19-23.

Benzie, I. F., \& Strain, J. J. (1996). The ferric reducing ability of plasma (FRAP) as a measure of "antioxidant power": the FRAP assay. Analytical Biochemistry, 239(1), $70-76$.

Berrios, J. D. J., Morales, P., Cámara, M., \& Sánchez-Mata, M. (2010). Carbohydrate composition of raw and extruded pulse flours. Food Research International, 43(2), $531-536$.

Cui, Y., Morgenstern, H., Greenland, S., Tashkin, D. P., Mao, J. T., Cai, L \& Zhang, Z. F. (2008). Dietary flavonoid intake and lung cancer-A population-based case-control Study. Cancer, 112(10), 2241-2248.

Dalgetty, D. D., \& Baik, B. K. (2003). Isolation and characterization of cotyledon fibers from peas, lentils, and chickpeas. Cereal Chemistry, 80(3), 310-315.

Delahunty, A., Perry, E., Wallace, A., Brand, J., \& Nuttall, J. (2019). Frost response in lentils. Paper presented at the GRDC Research Updates Series - Southern Region, Bendigo, Victoria, Australia. https://grdc.com.au/resources-and-publications/grdcupdate-papers/tab-content/grdc-update-papers/2019/02/frost-response-in-lentils 
329

330

331

332

333

334

335

336

337

338

339

340

341

342

343

344

345

346

347

348

349

350

351

352

353

354

Duenas, M., Hernandez, T., \& Estrella, I. (2006). Assessment of in vitro antioxidant capacity of the seed coat and the cotyledon of legumes in relation to their phenolic contents. Food Chemistry, 98(1), 95-103.

Dziki, D., Różyło, R., Gawlik-Dziki, U., \& Świeca, M. (2014). Current trends in the enhancement of antioxidant activity of wheat bread by the addition of plant materials rich in phenolic compounds. Trends in Food Science \& Technology, 40(1), 48-61.

Fleming, S. (1981). A study of relationships between flatus potential and carbohydrate distribution in legume seeds. Journal of Food Science, 46(3), 794-798.

Gilani, G. S., Xiao, C. W., \& Cockell, K. A. (2012). Impact of antinutritional factors in food proteins on the digestibility of protein and the bioavailability of amino acids and on protein quality. British Journal of Nutrition, 108(S2), S315-S332.

Hara, H., Haga, S., Aoyama, Y., \& Kiriyama, S. (1999). Short-chain fatty acids suppress cholesterol synthesis in rat liver and intestine. The Journal of Nutrition, 129(5), 942948.

Hollmann, J., Themeier, H., Neese, U., \& Lindhauer, M. G. (2013). Dietary fibre fractions in cereal foods measured by a new integrated AOAC method. Food Chemistry, 140(3), 586-589.

Li, M., van Esch, B. C., Wagenaar, G. T., Garssen, J., Folkerts, G., \& Henricks, P. A. (2018). Pro-and anti-inflammatory effects of short chain fatty acids on immune and endothelial cells. European Journal of Pharmacology, 831, 52-59.

Calderon-Montano, J., Burgos-Morón, E., Pérez-Guerrero, C., \& López-Lázaro, \& M. (2011). A review on the dietary flavonoid kaempferol. Mini Rreviews in Medicinal Chemistry, $11(4), 298-344$.

Ma, Z. F., \& Zhang, H. (2017). Phytochemical constituents, health benefits, and industrial applications of grape seeds: A Mini-Review. Antioxidants (Basel, Switzerland), 6(3), 71. doi:10.3390/antiox6030071 
355

356

357

358

359

360

361

362

363

364

365

366

367

368

369

370

371

372

373

374

375

376

377

378

379

380

381

382

Maharjan, P., Penny, J., Partington, D. L., \& Panozzo, J. F. (2019). The genotype and environment effects on the chemical composition and rheological properties of field peas. Journal of the Science of Food and Agriculture.

Martins, S. I., Jongen, W. M., \& Van Boekel, M. A. (2000). A review of Maillard reaction in food and implications to kinetic modelling. Trends in Food Science \& Technology, 11(9), 364-373.

Matthews, G. M., Howarth, G. S., \& Butler, R. N. (2012). Short-chain fatty acids induce apoptosis in colon cancer cells associated with changes to intracellular redox state and glucose metabolism. Chemotherapy, 58(2), 102-109.

McCleary, B. V.(2010). Development of an integrated total dietary fiber method consistent with the Codex Alimentarius definition. Cereal Foods World, 55(1), 24-28.

McDonald, L. S., Panozzo, J. F., Salisbury, P. A., \& Ford, R. (2016). Discriminant analysis of defective and non-defective field pea (Pisum sativum L.) into broad market grades based on digital image features. PloS One, 11(5), e0155523.

Menkovska, M., Levkov, V., Damjanovski, D., Gjorgovska, N., Knezevic, D., Nikolova, N., \& Andreevska, D. (2017). Content of TDF, SDF and IDF in cereals grown by organic and conventional farming-a short report. Polish Journal of Food and Nutrition sciences, 67(3), 241-244.

Mirali, M., Ambrose, S. J., Wood, S. A., Vandenberg, A., \& Purves, R. W. (2014). Development of a fast extraction method and optimization of liquid chromatographymass spectrometry for the analysis of phenolic compounds in lentil seed coats. Journal of Chromatography B, 969, 149-161.

Nuttall, J. G., Perry, E. M., Delahunty, A. J., O'Leary, G. J., Barlow, K. M., \& Wallace, A. J. (2018). Frost response in wheat and early detection using proximal sensors. Journal of Agronomy and Crop Science.

Portman, D., Blanchard, C., Maharjan, P., McDonald, L. S., Mawson, J., Naiker, M., \& Panozzo, J. F. (2018). Blending studies using wheat and lentil cotyledon flourEffects on rheology and bread quality. Cereal Chemistry, 95(6), 849-860.

This article is protected by copyright. All rights reserved 
383

384

385

386

387

388

389

390

391

392

393

394

395

396

397

398

399

400

401

402

403

404

405

406

407

408

Portman, D., Blanchard, C., Maharjan, P., Naiker, M., \& Panozzo, J. F. (2019). Water soluble carbohydrates (WSC) during fermentation and baking of composite wheat and lentil flour-Implications for enhanced functionality. Cereal Chemistry.

Rao, S., Santhakumar, A. B., Chinkwo, K. A., \& Blanchard, C. L. (2018). Q-TOF LC/MS identification and UHPLC-Online ABTS antioxidant activity guided mapping of barley polyphenols. Food Chemistry.

Rochfort, S., Ezernieks, V., Neumann, N., \& Panozzo, J. (2011). Pulses for human health: changes in isoflavone and saponin content with preparation and cooking. Australian Journal of Chemistry, 64(6), 790-797.

Rochfort, S., \& Panozzo, J. (2007). Phytochemicals for health, the role of pulses. Journal of Agricultural and Food Chemistry, 55(20), 7981-7994.

Siva, N., Johnson, C. R., Richard, V., Jesch, E. D., Whiteside, W., Abood, A. A., . . Thavarajah, D. (2018). Lentil (Lens culinaris Medikus) diet affects the gut microbiome and obesity markers in rat. Journal of Agricultural and Food Chemistry, $66(33), 8805-8813$.

Siva, N., \& Thavarajah, P. (2018). The impact of processing and cooking on prebiotic carbohydrates in lentil. Journal of Food Composition and Analysis, 70, 72-77.

Sparvoli, F., Laureati, M., Pilu, R., Pagliarini, E., Toschi, I., Giuberti, G., \& Bollini, R. (2016). Exploitation of common bean flours with low antinutrient content for making nutritionally enhanced biscuits. Frontiers in Plant s|Science, 7, 928.

Takruri, H. R., \& Issa, A. Y. (2013). Role of lentils (Lens culinaris L.) in human health and nutrition: A review. Mediterranean Journal of Nutrition and Metabolism, 6(1), 3-16.

Tosh, S. M., \& Yada, S. (2010). Dietary fibres in pulse seeds and fractions: Characterization, functional attributes, and applications. Food Research International, 43(2), 450-460.

Tuhumury, H. (2014). The effects of salts on the formation of gluten structure during hydration. (Unpublished ), RMIT University. 
409 Turfani, V., Narducci, V., Durazzo, A., Galli, V., \& Carcea, M. (2017). Technological, 410 nutritional and functional properties of wheat bread enriched with lentil or carob 411 flours. LWT-Food Science and Technology, 78, 361-366.

412 Van Loo, J., Cummings, J., Delzenne, N., Englyst, H., Franck, A., Hopkins, M., \& Quigley, 413 M. (1999). Functional food properties of non-digestible oligosaccharides: a consensus 414 report from the ENDO project (DGXII AIRII-CT94-1095). British Journal of $415 \quad$ Nutrition, 81(2), 121-132.

416 Van Soest, P., \& Robertson, J. (1981). The detergent system of analysis and its application to 417 human foods. The Analysis of Dietary Fiber in Foods. Marcel Dekker, New York. p, $123-158$.

419 Williams, B. A., Mikkelsen, D., Flanagan, B. M., \& Gidley, M. J. (2019). "Dietary fibre”: moving beyond the "soluble/insoluble" classification for monogastric nutrition, with an emphasis on humans and pigs. Journal of Animal Science and Biotechnology, $10(1), 45$.

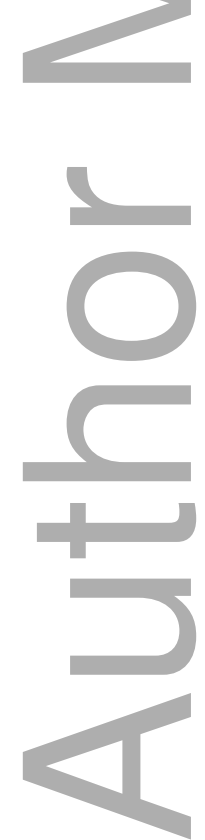


TABLE 1 Blending ratio of wheat and lentil flour

\begin{tabular}{lcc}
\hline Sample & Wheat Flour $(\mathrm{g})$ & Lentil Flour $(\mathrm{g})$ \\
\hline Wheat 100\% & 225.0 & 0 \\
Lentil 25\% & 180.0 & 45.0 \\
Lentil 50\% & 112.5 & 112.5 \\
Lentil 100\% & 0 & 225.0 \\
\hline
\end{tabular}

TABLE 2 Cookie baking formulation

\begin{tabular}{lc}
\hline Ingredients & Weight $(\mathrm{g})$ \\
\hline Shortening & 64 \\
Sugar & 130 \\
Sodium chloride & 2.1 \\
Sodium bicarbonate & 2.5 \\
Dextrose solution* & 33 \\
Water & 16 \\
Flour & 225 \\
\hline Notes* Dextrose solution consisted of $5.9 \mathrm{~g}$ \\
dextrose in 100 ml water.
\end{tabular}

Table 3 Effect of lentil flour concentration on cookie quality

\begin{tabular}{|c|c|c|c|c|c|c|c|}
\hline Blend & Height (mm) & $\begin{array}{c}\text { Weight } \\
\text { (g) }\end{array}$ & $\begin{array}{c}\text { Hardness } \\
\text { (N) }\end{array}$ & $\begin{array}{l}\text { Diameter Max } \\
\text { cm) }\end{array}$ & $\begin{array}{l}\text { Diameter } \\
\text { Min (cm) }\end{array}$ & $\begin{array}{l}\text { Area } \\
(\mathrm{cm} 2)\end{array}$ & $\begin{array}{c}\text { Lightness } \\
\left(\mathrm{L}^{*}\right)\end{array}$ \\
\hline $\begin{array}{l}\text { Wheat } \\
100 \%\end{array}$ & $9.2 \pm 0.3^{\mathbf{a}}$ & $18.4 \pm 1.3^{\mathbf{a}}$ & $3406 \pm 191^{a}$ & $7.1 \pm 0.1^{\mathbf{a}}$ & $6.8 \pm 0.1^{\mathbf{a}}$ & $38.3 \pm 0.6^{\mathbf{a}}$ & $65.2 \pm 0.3^{\mathbf{a}}$ \\
\hline $\begin{array}{l}\text { Lentil } \\
25 \%\end{array}$ & & $18.4 \pm 0.5^{\mathbf{a}}$ & $3684 \pm 125^{a}$ & $8.6 \pm 0.2^{\mathbf{b c}}$ & $8.3 \pm 0.3^{\mathbf{b}}$ & $56.5 \pm 2.7^{\mathbf{b}}$ & $61.8 \pm 0.6^{\mathbf{b}}$ \\
\hline $\begin{array}{l}\text { Lentil } \\
50 \%\end{array}$ & $8.2 \pm 0.1^{\mathbf{b}}$ & $17.3 \pm 0.5^{\mathbf{b}}$ & $3957 \pm 86^{\mathbf{b}}$ & $8.7 \pm 0.3^{\mathbf{b c}}$ & $8.3 \pm 0.4^{\mathbf{b}}$ & $57.2 \pm 4.2^{\mathbf{b}}$ & $52.3 \pm 0.9^{c}$ \\
\hline $\begin{array}{l}\text { Lentil } \\
100 \%\end{array}$ & $6.3 \pm 0.7^{\mathbf{c}}$ & $16.5 \pm 0.5^{\mathbf{c}}$ & $7015 \pm 184^{\mathbf{c}}$ & $8.85 \pm 0.3 \mathbf{c}$ & $8.5 \pm 0.3^{\mathbf{b c}}$ & $59.4 \pm 4.0^{\mathbf{c}}$ & $46.3 \pm 0.8^{d}$ \\
\hline
\end{tabular}


Note: Data are means \pm SD. Values in the same column with different alphabetical letters differed significantly as determined by ANOVA following a Tukey's HSD test $(\mathrm{P}<0.05)$.

TABLE 4 Concentration of raffinose family oligosaccharides (RFOs) in wheat-lentil cookies

\begin{tabular}{|c|c|c|c|c|}
\hline Blend $\quad$ Raffinose & Ciceritol & Stachyose & Verbascose & $\mathbf{R}+\mathrm{C}+\mathrm{S}+\mathrm{V}$ \\
\hline Wheat $100 \%$ & ND & ND & ND & ND \\
\hline $\begin{array}{l}\text { Premium } \\
\text { Lentil } 50 \% \\
\end{array}$ & $2.0 \pm 0.1^{\mathrm{a}}$ & $0.7 \pm 0.1^{\mathbf{a}}$ & $0.3 \pm 0.1^{\mathbf{a}}$ & $3.3 \pm 0.1^{\mathrm{a}}$ \\
\hline $\begin{array}{l}\text { Frosted } \\
\text { Lentil } 50 \%\end{array}$ & $1.9 \pm 0.1^{\mathrm{a}}$ & $0.8 \pm 0.1^{\mathbf{a}}$ & $0.3 \mathrm{t} \pm 0.1^{\mathrm{a}}$ & $3.2 \pm 0.1^{\mathbf{a}}$ \\
\hline $\begin{array}{l}\text { Premium } \\
\text { Lentil 100\% }\end{array}$ & $3.1 \pm 0.1^{\mathbf{b}}$ & $1.2 \pm 0.1^{\mathbf{b}}$ & $0.6 \pm 0.1^{\mathbf{b}}$ & $5.3 \pm 0.1^{\mathbf{b}}$ \\
\hline $\begin{array}{l}\text { Frosted } \\
\text { Lentil } 100 \%\end{array}$ & $3.2 \pm 0.1^{\mathbf{b}}$ & $1.3 \pm 0.1^{\mathbf{b}}$ & $0.6 \pm 0.1^{\mathbf{b}}$ & $5.5 \pm 0.1^{\mathbf{b}}$ \\
\hline
\end{tabular}

Note: ND; not detected. Data are means \pm SD. Values in the same column with different alphabetical letters differed significantly as determined by ANOVA following a Tukey's HSD test $(P<0.05)$.

TABLE 5 Peak identification using UPLC/QDa

\begin{tabular}{lllllll}
\hline Peak & Tentative Identification & Formula & $\mathbf{m} / \mathbf{z}^{[-]}$ & $\begin{array}{l}\text { Retention } \\
\text { Average }\end{array}$ & $\boldsymbol{\lambda}$ Max \\
& & & & Time & Mass & \\
\hline P1 & Kaempferol trihexose & $\mathrm{C}_{33} \mathrm{H}_{40} \mathrm{O}_{15}$ & 901.43 & 1.513 & 902 & $265 / 346$ \\
$\mathbf{P 2}$ & Kaempferol glycoside & $\mathrm{C}_{15} \mathrm{H}_{10} \mathrm{O}_{6}$ & 477.25 & 1.651 & 478 & $265 / 346$ \\
\hline P3 & Procyanidin & $\mathrm{C}_{33} \mathrm{H}_{40} \mathrm{O}_{15}$ & 577.07 & 1.513 & 578 & $279 / 218$ \\
\hline
\end{tabular}


A

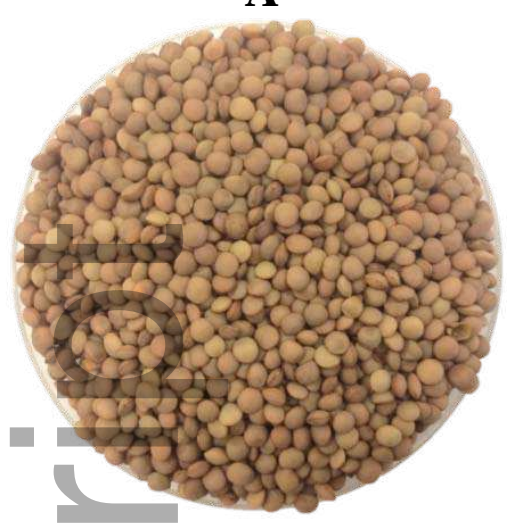

B

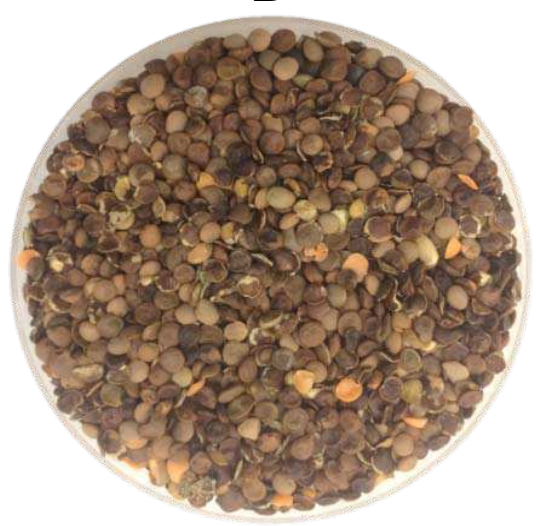

FIGURE 1 (A) Premium grade red lentils with a mean seed size of $4.5 \mathrm{~mm}$, uniform colour and characteristic lens shape. (B) Down-graded red lentils affected by frost with a majority seed size below $3.5 \mathrm{~mm}$, major discoloration as well as damaged split and malformed seed.

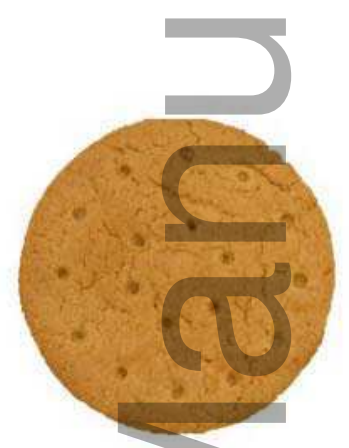

Wheat $100 \%$

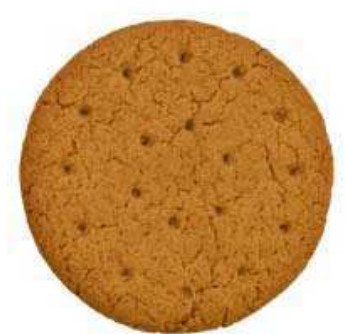

Lentil $25 \%$

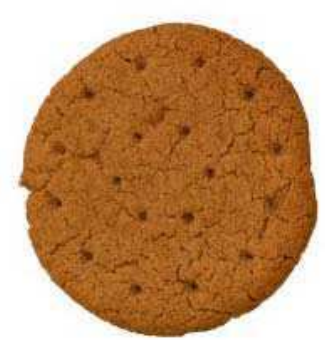

Lentil 50\%

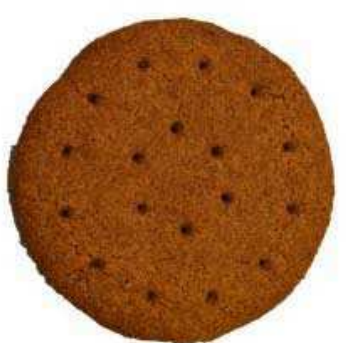

Lentil $100 \%$

FIGURE 2 Wheat-lentil composite cookies baked using different concentrations of lentil flour with wheat.

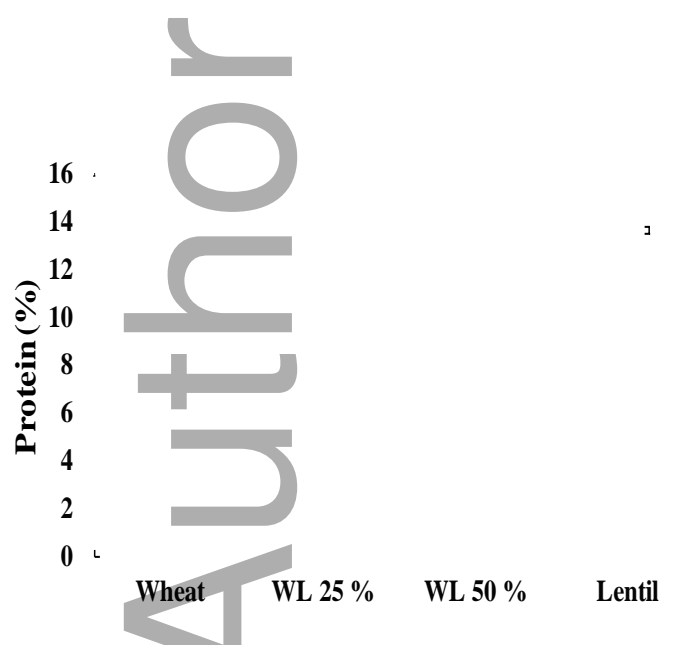

FIGURE 3 A: Comparison of $\%$ protein and $3 \mathrm{~B}$ : \% fiber of composite wheat-lentil cookies: (WL). Letters that are the same are not significantly different $(p<0.05)$. 


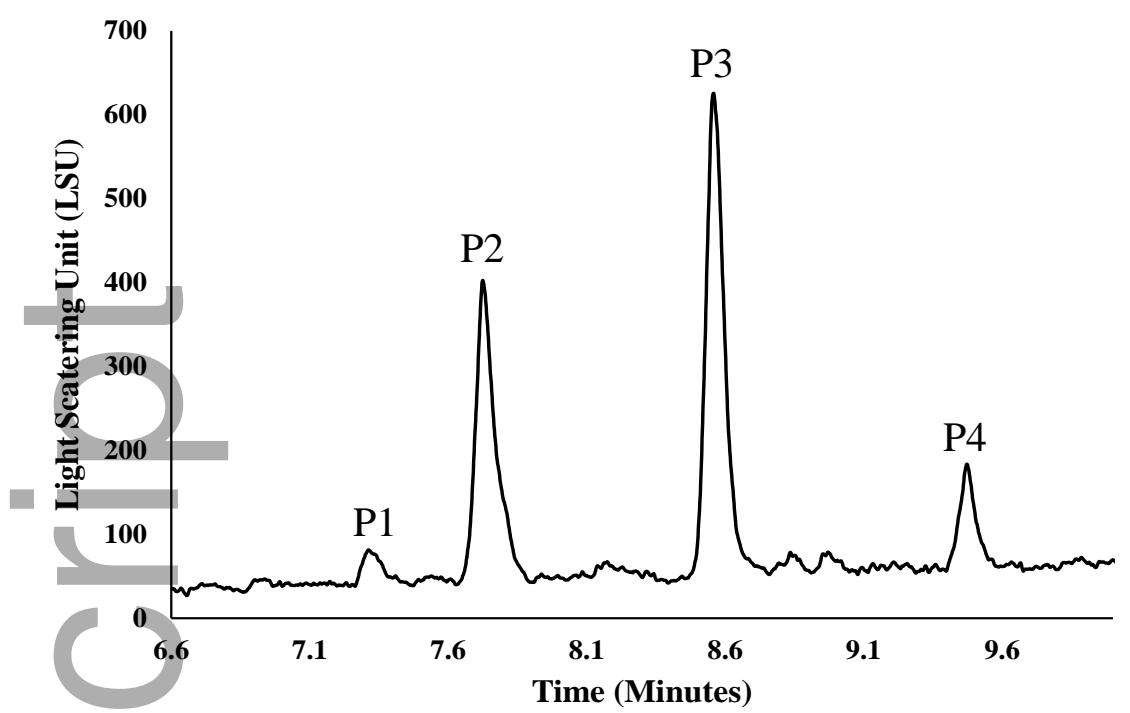

FIGURE 4 Chromatogram of oligosaccharides in a 50\% frost damaged wheat-lentil cookie, (peaks: 1, raffinose; 2, ciceritol; 3, stachyose; and 4, verbascose).

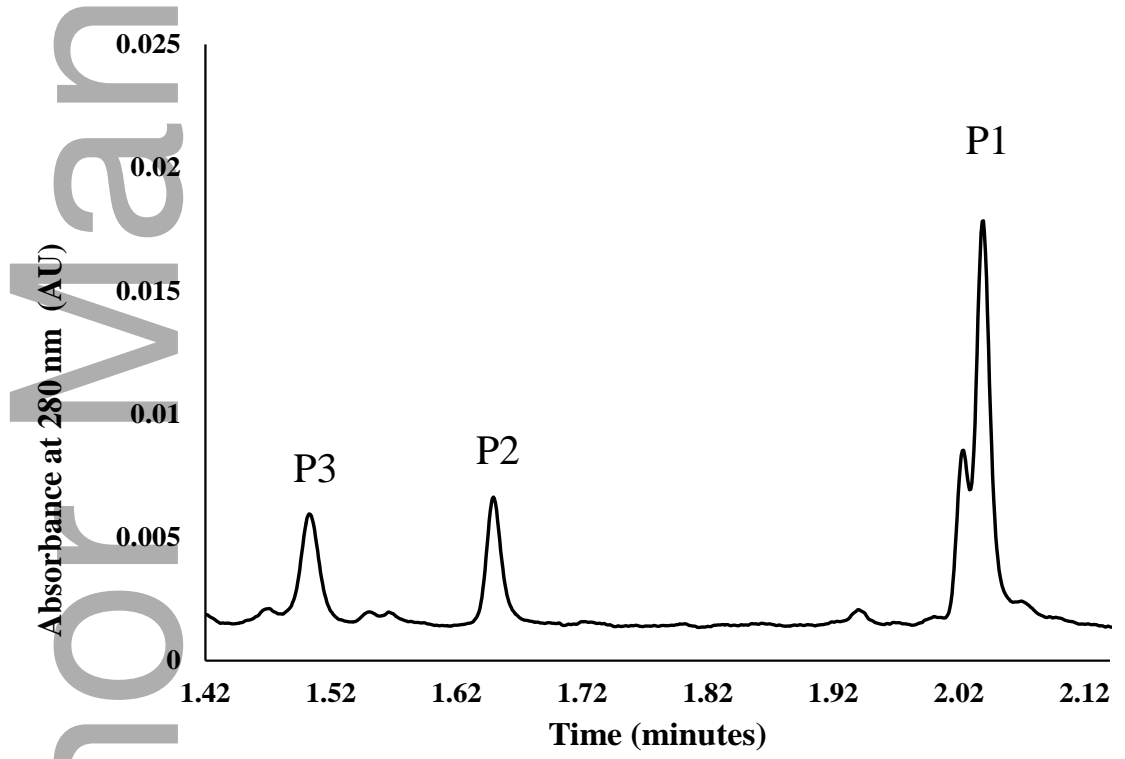

FIGURE 5 Chromatogram comparing the phenolic acids detected in 50\% wheat-lentil cookies. Premium lentil; solid line, and frost damaged lentil; broken line. Peaks P1; Kaempferol trihexose, P2; Kaempferol glycoside, P3; Procyanidin. 


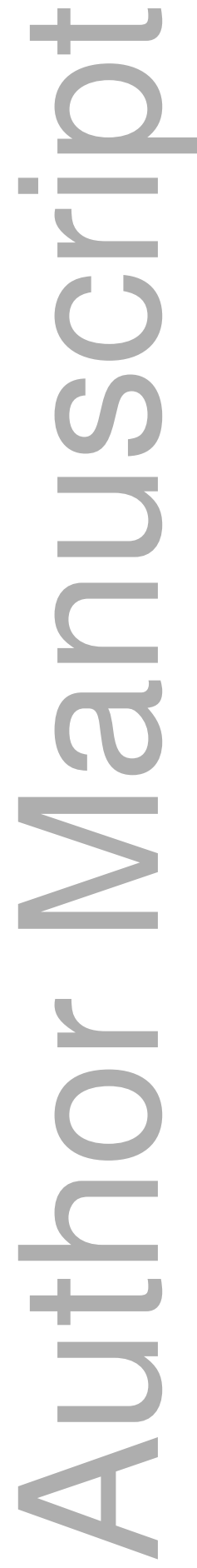

This article is protected by copyright. All rights reserved 


\section{University Library}

\section{- M I I N E R VA \\ A gateway to Melbourne's research publications}

Minerva Access is the Institutional Repository of The University of Melbourne

Author/s:

Portman, D;Maharjan, P;McDonald, L;Laskovska, S;Walker, C;Irvin, H;Blanchard, C;Naiker, M;Panozzo, JF

Title:

Nutritional and functional properties of cookies made using down-graded lentil - A candidate for novel food production and crop utilization

Date:

2020-01-01

Citation:

Portman, D., Maharjan, P., McDonald, L., Laskovska, S., Walker, C., Irvin, H., Blanchard, C., Naiker, M. \& Panozzo, J. F. (2020). Nutritional and functional properties of cookies made using down-graded lentil - A candidate for novel food production and crop utilization. Cereal Chemistry, 97 (1), pp.95-103. https://doi.org/10.1002/cche.10232.

Persistent Link:

http://hdl.handle.net/11343/286592 